\title{
Two-stage aqueous drainage tube implant with pericardial graft patch
}

\author{
Minak Bhalla $\mathbb{C}^{1} \cdot$ Sheila Luk $^{1} \cdot$ Rohit Jolly $^{1} \cdot$ Faisal Ahmed $^{2}$ \\ Received: 12 March 2019 / Accepted: 26 March 2019 / Published online: 11 April 2019 \\ (c) The Royal College of Ophthalmologists 2019
}

Advanced glaucoma can often be refractory to medical/laser treatments and surgical intervention is essential to preserve vision. In cases with unsuccessful primary trabeculectomies, the next common surgical option is to incorporate a Baerveldt 250 Glaucoma Drainage Device (GDD) in the anterior chamber via a corneal incision for additional outflow of aqueous humour to the subconjunctival space $[1,2]$. This can be particularly challenging in patients who have pre-existing inflammatory conditions and have damaged sclera [1]. This short article describes a novel use of Tutoplast (Innovative Ophthalmic Products, Costa Mesa, California, USA) for scleral reinforcement before implantation of GDD over two operations.

Patient 1 is a 56-year-old lady with uncontrolled advanced open-angle glaucoma and chronic scleritis. She previously lost vision in the left eye after unsuccessful trabeculectomies, diode laser, Molteno tube surgery, and a failed penetrating keratoplasty. Her only seeing right eye had scleromalacia from recurrent scleritis and sustained high pressure, despite a previous trabeculectomy and endocyclophotocoagulation (to spare the sclera). In light of this, a two-staged tube surgery was planned; the first stage consisted of a superior peritomy, and then reinforcing the existing thin sclera from the limbus with Tutoplast. The Tutoplast was trimmed to fit the scleral bed for the Baerveldt plate and tube. Two layers of the pericardial graft were attached onto the sclera with Tisseel glue (Baxter AG, Vienna, Austria). The conjunctiva was repositioned, glued and sutured to the limbus. After 2 weeks, the patient underwent the second stage, where the GDD was placed over the Tutoplast, and the plate was sutured. A 7/0

Minak Bhalla

m.bhalla@nhs.net

1 Moorfields Eye Hospital Trust, London, UK

2 Western Eye Hospital, Imperial Healthcare Trust, London, UK
Supramid suture was placed to occlude the GDD lumen. The GDD was inserted into the anterior chamber through a superotemporal limbal tunnelled incision. A thinned double layer of Tutoplast was glued on the tube and the conjunctiva was placed over the graft (Figs. 1 and 2).

Patient 2 is a 67-year-old lady with rheumatoid arthritis and secondary chronic uveitic glaucoma. She too had uncontrolled progressive glaucoma with visual deterioration despite treatment. She also had severe scleromalacia secondary to recurring scleritis. Since previous interventions included a failed trabeculectomy and endocyclophotocoagulation, she was listed to have a GDD. Once again, this was approached in a two-step manner, where the pericardial graft was glued in the right eye prior to the implantation of GDD.

In the two resistant glaucoma patients with scleromalacia, reinforcing the existing scleral tissue before implantation of GDD was their only option to prevent blindness. The concept of a two-step procedure allows the eye to incorporate the Tutoplast and ensure that subsequent manipulation would be safe and effective for plate fixation [3]. Alternatively, in a thinned scleral the site of implantation could be changed; however, evidence suggests that inferior tubes increase the risk of exposure, which may risk endophthalmitis [4]. This is explained by gravitational

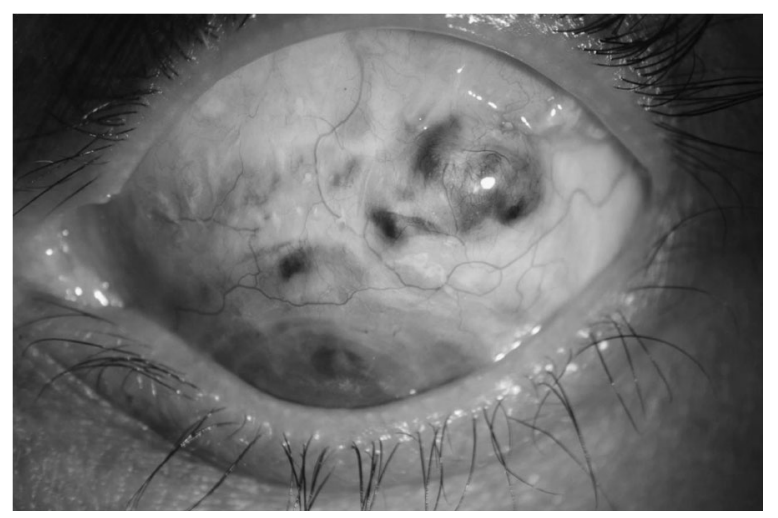

Fig. 1 Patient 1 's left eye with marked scleromalacia, especially superotemporally post removal of a failed Molteno tube 


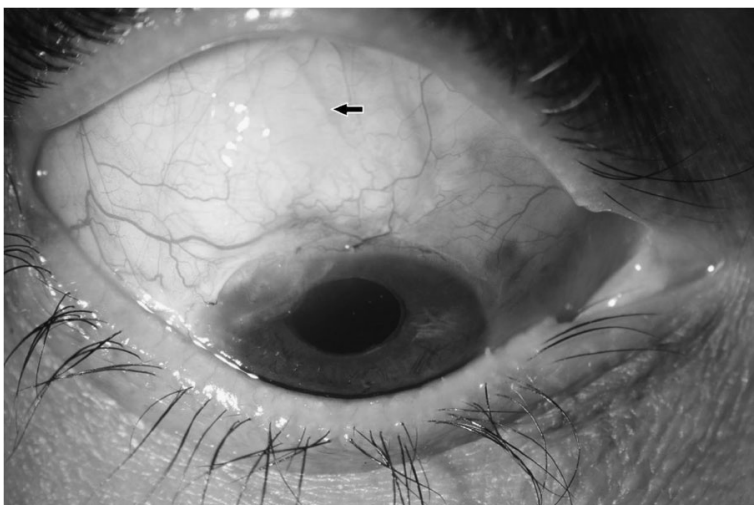

Fig. 2 Patient 1 's right eye post insertion of the pericardium graft superotemporally for reinforcement of sclera prior to Baerveldt (Advanced Medical Optics, Santa Ana, California, USA) tube implantation (black arrow)

transit of the tear film to the lower lid, which increases pooling of commensal organisms near the inferior tube.

Despite a recent survey highlighting glaucoma surgeons preferring trabeculectomies over GDD in advanced glaucoma, they remain contraindicated in scleromalacia patients due to the risk of perforation [5]. The concept of a two-step GDD procedure allowed a safe and effective outcome for recalcitrant glaucoma patients with scleral thinning.

\section{Compliance with ethical standards}

Conflict of interest The authors declare that they have no conflict of interest.

Publisher's note: Springer Nature remains neutral with regard to jurisdictional claims in published maps and institutional affiliations.

\section{References}

1. Marchini G, Ceruti P, Vizzari G, Amantea C, Marchetti P. Longterm outcomes of modified technique using Baerveldt glaucoma implant for the treatment of refractory glaucoma implant for the treatment of refractory glaucoma. J Glaucoma. 2016;25:952-8.

2. Gedde SJ, Schiffman JC, William JF, Leon W, Herndon MD, Brandt JD, et al. Treatment outcomes in tube versus trabeculectomy (TVT) study after 5 years of follow up. Am J Ophthalmol. 2012;153:789-803.

3. Novitskaya ES, Clifford L, Vivian AJ. Tutoplast pericardium patch graft for scleral thinning following strabismus surgery. Eye. 2013;27:682-3.

4. Kwon HJ, Kerr N, Ruddle JB, Ang GS. Endophthalmitis associated with glaucoma shunt intraluminal stent exposure. J Curr Glaucoma Pract. 2016;10:36-37.

5. Rodriguez-Una I, Azuara-Blanco A, King AJ. Survey of glaucoma surgical preferences and post-operative care in the United Kingdom. Clinical Exp Ophthalmol. 2016;45:232-40.

\title{
Intraoperative real-time image-guided ab externo canaloplasty
}

\author{
Rino Frisina ${ }_{(\mathbb{D})}^{1} \cdot$ Alessandro Meduri ${ }^{2}$
}

Received: 30 September 2018 / Revised: 2 February 2019 / Accepted: 20 March 2019 / Published online: 25 April 2019

(C) The Royal College of Ophthalmologists 2019

\section{Introduction}

Real-time image-guided surgery is spreading in different surgical fields for its potential to improve surgical outcome

Rino Frisina

frisinarino@gmail.com

1 Department of Ophthalmology of University of Padova via Giustiniani 2, Padova 35128, Italy

2 Department of Surgical Specialties, Ophthalmology Clinic, University of Messina, Messina 98100, Italy and numerous types of imaging devices are available today [1-5]. The purpose of this study is to evaluate the role of intraoperative ultrasound biomicroscopy (iUBM) and optical coherence tomography (iOCT) for monitoring morphological changes of anterior chamber (AC) structures during ab externo canaloplasty for treating open angle glaucoma (OAG).

\section{Material and methods}

Consecutive patients affected by OAG refractory to topical therapy were enrolled and underwent ab externo 

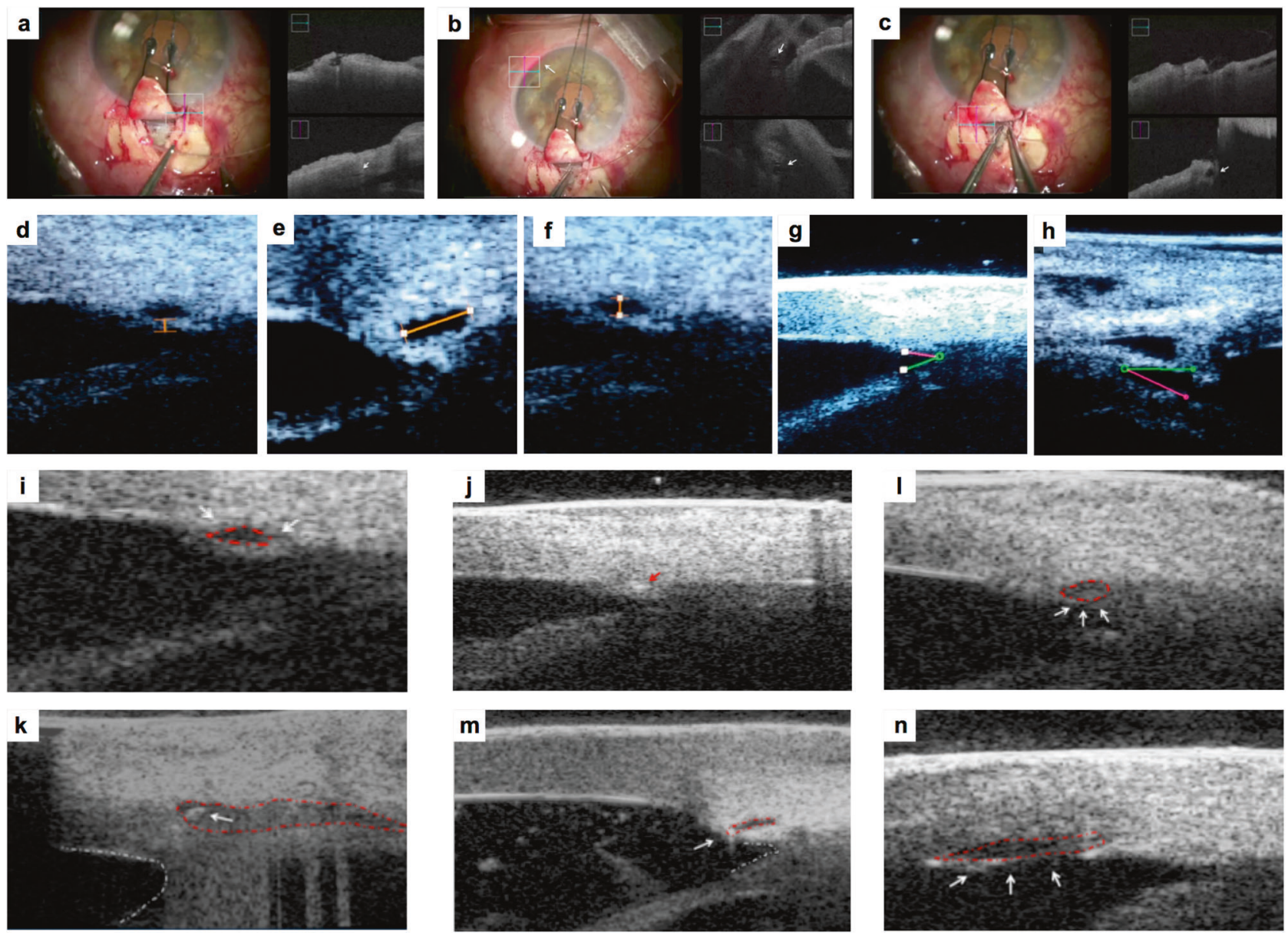

Fig. 1 Picture a Microscope image (left picture) shows trabeculodescemetic window after dissection of the deep scleral flap. iOCT image (right picture) shows SC before dilating the ostium of SC using the iTrack microcatheter (white arrow). Picture b Microscope image (left picture) shows the progress of microcatheter into SC. Red light indicates the position of the microcatheter tip in the SC. iOCT image (right picture) shows the microcatheter in the SC (white arrows) Picture c Microscope imaging shows the final step of retraction of the microcatheter with simultaneous injection of Healon GV into the SC. iOCT image (right picture) shows the enlarged SC (white arrow) Picture d Intraoperative UBM image: TM thickness measurement after SC viscodilation. Picture e, f Intraoperative UBM image: horizontal and vertical diameter of SC after viscodilation. Picture $\mathbf{g}, \mathbf{h}$ Intraoperative UBM image: AC angle before (g) and after surgery (h) Picture i Preoperative iUBM shows SC that appears as an anechogenic oval-shaped space (red dashed line), and TM (white arrow) Picture $\mathbf{j}$ iUBM shows the microcatheter in the SC that appears hyperechogenic in comparison to the surrouding tissue (red arrow) Picture l: iUBM shows enlarged SC after viscodilation (white arrows, red dashed line) Picture k: iUBM shows SC with suture before tensioning suture (white arrow), deep scleral dissection and filtering window (red dashed line). AC angle appears with a concave and rounded profile (white dashed line) Picture $\mathbf{m}$ iUBM shows SC and suture after tensioning suture (white arrow). SC appears elongated (red dashed line) and $\mathrm{AC}$ angle becomes acute (white dashed line) Picture $\mathbf{n}$ iUBM shows Descemet's membrane detachment after viscodilation (white arrows and red dashed line)

Table 1 Demographic and clincal preoperative data of patients

\begin{tabular}{llllllll}
\hline No. & Age (years) & $\begin{array}{l}\text { Gender male } \\
\text { (m)/female (f) }\end{array}$ & IOP, mmHg & $\begin{array}{l}\text { BCVA } \\
\text { logMAR }\end{array}$ & $\begin{array}{l}\text { lens status phakic } \\
\text { (p)/pseudophakic (pp) }\end{array}$ & $\begin{array}{l}\text { AL, mm } \\
\text { type }\end{array}$ \\
\hline 1 & 67 & $\mathrm{f}$ & 34 & 0.6 & $\mathrm{P}$ & 24.7 & POAG \\
2 & 72 & $\mathrm{~m}$ & 36 & 0.5 & $\mathrm{P}$ & 23.5 & POAG \\
3 & 68 & $\mathrm{~m}$ & 26 & 0.8 & $\mathrm{P}$ & 22.8 & POAG \\
4 & 50 & $\mathrm{f}$ & 22 & 0 & $\mathrm{P}$ & 25.8 & POAG \\
5 & 75 & $\mathrm{~m}$ & 31 & 0.1 & $\mathrm{PP}$ & 24.9 & POAG \\
6 & 61 & $\mathrm{~m}$ & 29 & 0.1 & $\mathrm{P}$ & 24 & POAG
\end{tabular}


Table 1 (continued)

\begin{tabular}{|c|c|c|c|c|c|c|c|}
\hline No. & Age (years) & $\begin{array}{l}\text { Gender male } \\
(\mathrm{m}) / \text { female }(\mathrm{f})\end{array}$ & $\mathrm{IOP}, \mathrm{mmHg}$ & $\begin{array}{l}\text { BCVA } \\
\text { logMAR }\end{array}$ & $\begin{array}{l}\text { lens status phakic } \\
\text { (p)/pseudophakic (pp) }\end{array}$ & $\mathrm{AL}, \mathrm{mm}$ & $\begin{array}{l}\text { Glaucoma } \\
\text { type }\end{array}$ \\
\hline 7 & 49 & $\mathrm{f}$ & 29 & 0 & $\mathrm{P}$ & 23.7 & POAG \\
\hline 8 & 77 & $\mathrm{~m}$ & 27 & 0 & PP & 22.9 & POAG \\
\hline 9 & 69 & $\mathrm{f}$ & 30 & 0.6 & $\mathrm{P}$ & 23.4 & POAG \\
\hline 10 & 45 & $\mathrm{~m}$ & 24 & 0 & $\mathrm{P}$ & 24.2 & POAG \\
\hline 11 & 71 & $\mathrm{f}$ & 26 & 0 & PP & 25.4 & POAG \\
\hline 12 & 72 & $\mathrm{~m}$ & 28 & 0.4 & $\mathrm{P}$ & 23.8 & POAG \\
\hline 13 & 69 & $\mathrm{f}$ & 26 & 0.2 & PP & 22.5 & POAG \\
\hline 14 & 49 & $\mathrm{f}$ & 24 & 0 & $\mathrm{P}$ & 22.9 & POAG \\
\hline 15 & 42 & $\mathrm{~m}$ & 31 & 0 & $\mathrm{P}$ & 24.2 & POAG \\
\hline 16 & 51 & $\mathrm{f}$ & 28 & 0 & $\mathrm{P}$ & 25.1 & PEX \\
\hline 17 & 47 & $\mathrm{~m}$ & 26 & 0 & $\mathrm{P}$ & 25.7 & PEX \\
\hline 18 & 58 & $\mathrm{f}$ & 24 & 0 & $\mathrm{P}$ & 22.8 & PG \\
\hline 19 & 46 & $\mathrm{~m}$ & 23 & 0 & $\mathrm{P}$ & 23.1 & PG \\
\hline 20 & 33 & $\mathrm{f}$ & 21 & 0 & $\mathrm{P}$ & 24.6 & UG \\
\hline $\begin{array}{l}\text { Total mean } \pm \\
\text { (range) } * \% * *\end{array}$ & $\begin{array}{l}58.5 \pm 12.96 \\
(33-77)\end{array}$ & $50 \% / 50 \%$ & $\begin{array}{l}27.3 \pm 3.9 \\
(21-36)\end{array}$ & $\begin{array}{l}0.14 \pm 0.2 \\
(0.8-0)\end{array}$ & $80 \% / 20 \%$ & $\begin{array}{l}24 \pm 1.02 \\
(22.5-25.8)\end{array}$ & $\begin{array}{l}75 \% / 10 \% / \\
10 \% / 5 \%\end{array}$ \\
\hline
\end{tabular}

$A L$ axial lenght, $B C V A$ best-corrected visual acuity, $I O P$ intraoucular pressure, $P E X$ pseudoespholiative glaucoma, $P G$ pigmentary, $P O A G$ primary open angle glaucomaglaucoma, $U G$ uveitic glaucoma

*Mean \pm (range) for quantitative parameters

*Percentage for qualitative parameters

canaloplasty (iTrack ${ }^{\mathrm{TM}}$, Ellex iScience, Inc., Fremont, CA, USA) between January and June 2017. The study was approved by hospital ethics committee and informed consent from all patients was obtained. Surgery was performed by one surgeon (R.F.). Demographic and preoperative parameters were as follows: age, gender, eye, glaucoma type, intraocular pressure (IOP), best-corrected visual acuity (BCVA), lens status, and axial length. IOP and BCVA were monitored at 1,3 and 6 postoperative months. iOCT integrated on to a microscope (OPMI Lumera 700, RESCAN 700 spectral domain-OCT wavelength $840 \mathrm{~nm}$, Carl Zeiss Meditec, Jena, Germany) and iUBM (iUltrasound iscience interventional ${ }^{\mathrm{TM}}$, Menlo Park CA, 80 megaHertz transducer frequency) were used for evaluating the morphological changes of AC structures and for measuring the diameters of Schlemm canal (SC), trabecular meshwork (TM) thickness and AC angle during the surgery.

\section{Results}

Twenty eyes (20 patients) were recruited (Table 1). IOP decreased significantly during follow-up (from $27.3 \pm 3.9$ to $14.5 \pm 2.5 \mathrm{mmHg}$ ). BCVA improved only in patients who underwent cataract surgery ( 6 out of 20 ).
iOCT allowed the surgeon to monitor SC and AC angle changes during microcatheter passage and viscodilation. During viscodilation SC changed its profile from oval to round-shape with hyporeflective content (Fig. 1a-c). The poor quality of iOCT imaging did not allow the observer to obtain accurate measurements.

TM thickness, SC diameters and AC angle were measured by iUBM. TM thickness mean was $92 \pm 20.6 \mu \mathrm{m}$. Horizontal and vertical diameters mean of SC were, respectively, $410 \pm 56$ and $110 \pm 23 \mu \mathrm{m}$ during viscodilation. AC angle mean was reduced from $25.8^{\circ} \pm 11^{\circ}$ to $24.5^{\circ} \pm 14^{\circ}$ after tensioning suture and its profile changed from concave to acute. SC appeared as an anechogenic oval-shaped space. Microcatheter into SC appeared hyperechogenic. In one case endothelial detachment was detected during viscodilation (Fig. 1d-n).

\section{Discussion}

iOCT allowed the surgeon to monitor morphological changes of $\mathrm{AC}$ structures during surgery but scanning acquisition was not immediate requiring continual adjustment of the focus and scanning point due to the eye movements during surgery that changed the depth of the plan of visualization. The limit of iOCT was the short penetration depth, responsible for 
shadowing of scleral tissue and of overlapping and inverted images. Anyhow, iOCT was the best option to obtain a high resolution for imaging superficial areas. Instead iUBM was useful in detecting deeper structures, giving sharper images to measure morphological changes of AC structures. However, the image acquisition required interrupting surgery and the contact of the probe with the eye.

Intraoperative real-time image-guided surgery represents the future even if it still requires further efforts to make the instrumentation functional and simple to use.

\section{Compliance with ethical standards}

Conflict of interest The authors declare that they have no conflict of interest.

Publisher's note: Springer Nature remains neutral with regard to jurisdictional claims in published maps and institutional affiliations.

\section{References}

1. Li X, Wei L, Dong X, Huang P, Zhang C, He Y, et al. Microscopeintegrated optical coherence tomography for image-aided positioning of glaucoma surgery. J Biomed. 2015;20:76001.

2. Kumar RS, Jariwala MU, V SA, Venugopal JP, Puttaiah NK, Balu R, et al. A pilot study on feasibility and effectiveness of intraoperative spectral-domain optical coherence tomography in glaucoma procedures. Transl Vis Sci Technol. 2015;4:1-9.

3. Yan X, Li M, Chen Z, Zhu Y, Song Y, Zhang H. Schlemm's canal and trabecular meshwork in eyes with primary open angle glaucoma: a comparative study using high-frequency ultrasound biomicroscopy. PLoS One. 2016;4:11.

4. Siebelmann S, Cursiefen C, Lappas A, Dietlein T. Intraoperative optical coherence tomography enables noncontact imaging during canaloplasty. J Glaucoma. 2016;25:236-8.

5. Xj Zhu, Zhang KK, He WW, Sun XH, Meng FR, Lu Y. Diagnosis of pupillary block glaucoma after removal of congenital cataract cataracts with intraoperative ultrasound biomicroscopy: a case report. BMC Ophthalol. 2016;16:58 https://doi.org/10.1186/s12886-016-0238-9.

\title{
Comment on: Pressure and velocity in intraocular and subarachnoid space fluid chambers: an inseparable couple
}

\author{
Joshua P. Harvey (D) ${ }^{1}$ \\ Received: 25 March 2019 / Accepted: 8 April 2019 / Published online: 11 June 2019 \\ (c) The Royal College of Ophthalmologists 2019
}

To the Editor,

I thank Killer et al. for their interesting article regarding the relationship between pressure and velocity, and its implications on aqueous humour turnover [1]. The authors use a combination of the Bernoulli and the Navier-Stokes equations to demonstrate that flow rate of a fluid is a function of both its pressure and velocity. The authors conclude that a high pressure, IOP, results in a lower aqueous velocity. They go onto hypothesise that a low aqueous velocity leads to a reduced turnover of toxic substances in the anterior chamber which likely plays an important role in the pathogenesis of glaucoma. The assumption in their

Joshua P. Harvey

Joshua.harvey@ doctors.org.uk

1 Ophthalmology Department, King's College Hospital, SE5 9RS London, United Kingdom conclusion is that aqueous flow remains constant. If, however, flow were to increase as a function of IOP then velocity may remain constant, or may even increase, thus breaking the inseparable coupling of pressure and velocity alluded to in the authors' title.

The Goldman equation demonstrates that in fact aqueous flow does vary with IOP:

$C=F /\left(\mathrm{IOP}-\mathrm{P}_{\mathrm{e}}\right)$

Rearranged:

$F=C \times\left(\mathrm{IOP}-\mathrm{P}_{\mathrm{e}}\right)$

where $C$ is outflow facility, $F$ is outflow rate and $P_{\mathrm{e}}$ is episcleral venous pressure.

Therefore, as IOP increases, so does the outflow rate. A number of experiments have demonstrated this to be true, and that aqueous flow does not remain constant as the authors have assumed (Fig. 1) [2]. 


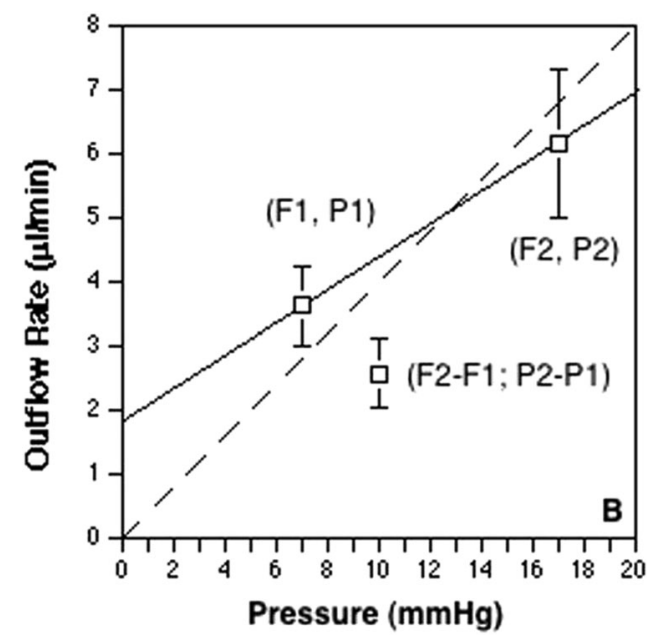

Fig. 1 Aqueous outflow as a result of changes of anterior segment pressure. Taken with permission from Tian et al. experiment on monkey organ-cultured anterior segment data. The dashed line represents a hypothesised relationship between outflow rate and pressure

Outflow facility as a function of intraocular pressure in cultured anterior segments of enucleated monkey eyes (Fig. 1). The solid line represents a secant between F1, P1 and F2, P2. This line is unlikely to be physiological at all IOPs given it has a positive y intercept. The relationship between $\mathrm{F}$ and $\mathrm{P}$ is therefore positive, but nonlinear [2].

In comparison to aqueous drainage, its production has been shown to be relatively independent of IOP fluctuations $[3,4]$. However, the continuity equation dictates that once IOP stabilises, aqueous production must equal aqueous drainage.

$A_{1} v_{1}=A_{2} v_{2}$

Where $A$ is the cross sectional area of the fluid and $v$ is velocity.

In the setting of increased aqueous outflow secondary to raised IOP there are only two possible responses regarding aqueous production. The first possibility is increased outflow will cause a reduction in IOP, which will then lead to the aqueous drainage returning to normal. This is well demonstrated with computational modelling and likely demonstrates a homeostatic response in normal eyes [2]. The second possibility is that despite increased aqueous drainage, IOP remains high and therefore aqueous production must rise to match drainage.

Neither of these situations support the inversely proportional relationship between pressure and velocity that Killer et al. have described. It is true that in an idealised singlefluid compartment described by the Bernoulli equation, if there is a steady state flow, a raised IOP will be accompanied by a reduction in velocity. However, it is unlikely that such a system accurately represents the physiological eye. Furthermore, experimental evidence contradicts the author's hypothesis by demonstrating that a raised IOP results in greater flow, with significant increases in outflow. It is therefore possible that the authors have erroneously attributed a change in aqueous velocity as a primary mechanism in the pathophysiology of glaucoma.

\section{Compliance with ethical standards}

Conflict of interest The author declares that he has no conflict of interest.

Publisher's note: Springer Nature remains neutral with regard to jurisdictional claims in published maps and institutional affiliations.

\section{References}

1. Killer HE, Hou R, Wostyn P, Meyer P, Pircher A. Pressure and velocity in intraocular and subarachnoid space fluid chambers: an inseparable couple. Eye. 2019;33:343-6.

2. Tian B, Hu Y, Gabelt BT, Kaufman PL. Factors affecting outflow facility calculations. Exp Eye Res. 2006;83:1515-20.

3. Kiel JW, Hollingsworth M, Rao R, Chen M, Reitsamer HA. Ciliary blood flow and aqueous humor production. Prog Retin Eye Res. 2011;30:1-17.

4. Brubaker RF. Flow of aqueous humor in humans [The Friedenwald Lecture]. Invest Ophthalmol Vis Sci. 1991;32:3145-66. 


\title{
Response to: 'Comment on: Pressure and velocity in intraocular and subarachnoid space fluid chambers: an inseparable couple'
}

\author{
Hanspeter E. Killer ${ }^{1,2}$ - Achmed Pircher ${ }^{1,3}$ \\ Received: 16 April 2019 / Accepted: 16 April 2019 / Published online: 14 June 2019 \\ (C) The Royal College of Ophthalmologists 2019
}

To the Editor

We appreciate the thoughtful letter [1] by Dr. Harvey concerning our paper Pressure and velocity - an inseparable couple [2], which might have caused some confusion that we would like to clarify.

Dr. Harvey's concerns are focused exclusively on the situation in the anterior chamber of the eye in glaucoma, whereas we first considered cerebrospinal fluid (CSF) in the subarachnoid space of the optic nerve. We then added the behaviour of aqueous humour in the anterior chamber as a partial analogy to the CSF in the subarachnoid space (SAS). In his letter Dr. Harvey mentions the term "flow rate" (volume per time: $Q=V / t$ ), a term we never addressed in our paper.

The comments of Dr. Harvey may, however, help to clarify matters that have troubled other readers.

The subarachnoid space of the optic nerve is connected to the intracranial CSF spaces via the optic canal. CSF flows into the SAS from the pituitary cistern. This outflow pathway is not yet fully understood, but includes a lymphatic pathway in the dura of the optic nerve sheath [3].

While the inflow pathway consists of one route (via the optic canal), the outflow pathway may probably consist of a series of lymphatic clefts (and probably lymphatic pathways) [4] and maybe a reversed flow of fluid back to the optic canal. However, these structures can be considered as one outflow route (consisting of multiple small entities). In patients with elevated intracranial pressure, the diameter of

Hanspeter E. Killer

profesrielkiller@gmail.com

1 Department of Ophthalmology, Kantonsspital Aarau, Aarau, Switzerland

2 Department of Ophthalmology, University Hospital Basel, Basel, Switzerland

3 Department of Neuroscience/Ophthalmology, Uppsala University, Uppsala, Sweden the optic nerve sheath increases due to elevated pressure that is accompanied by lower velocity.

The relationship of pressure and velocity still works in the CSF space surrounding the optic nerve. We then theorised about the fluid dynamics in the anterior chamber in glaucoma.

We agree with Harvey as he rightly states: it is true that in an idealised single-fluid compartment described by the Bernoulli equation, if there is a steady flow, a raised IOP will be accompanied by a reduction in velocity. Full stop. However, this is what we described in our paper as shown in the figure on page 2 . We did not claim to have created a fluid model of the eye and the anterior chamber. We simplified the anatomy in an analogy of the subarachnoid space, and we are aware that the anatomical situation of the eye is of course more complex. This however does not invalidate the model in its principal conception.

Just as in the subarachnoid space, in the anterior chamber, there is one inflow route of aqueous humour from the ciliary body and basically one outflow route via Schlemm's canal and the uveoscleral pathway [5]. Although the outflow resistance in these two pathways may differ, they can function as one route. Of course, the aqueous flow varies with intraocular pressure as shown in the Goldman formula. However, a higher intraocular pressure (as in glaucoma) is not expected to increase outflow in a linear fashion. If this were the case, intraocular pressure would indeed not be a problem in glaucoma. That is why we lower the intraocular pressure in glaucoma with eyedrops or surgical techniques. Untreated intraocular pressure just levels on a higher scale — and the couple remains loyal although — of coursenot in a linear fashion.

We did not, as Dr. Harvey suggested, "erroneously" attribute a change in aqueous velocity as a primary mechanism of the pathophysiology of glaucoma, but described fluid behaviour in fluid compartments. Glaucoma is a disease with many components and pathomechanisms. Stagnation of aqueous humour might be one of them.

Prof. Habil, Dr. H.E. Killer and Dr. A. Pircher for the group. 


\section{Compliance with ethical standards}

Conflict of interest The authors declare that they have no conflict of interest.

Publisher's note: Springer Nature remains neutral with regard to jurisdictional claims in published maps and institutional affiliations.

\section{References}

1. Harvey JP. Comment on: Pressure and velocity in intraocular and subarachnoid space fluid chambers: an inseparable couple. Eye. 2019; https://doi.org/10.1038/s41433-019-0487-y. [Epub ahead of print].
2. Killer HE, Hou R, Wostyn P, Meyer P, Pircher A. Pressure and velocity in intraocularand subarachnoid space fluid chambers: an inseparable couple. Eye. 2019;33:343-6.

3. Killer HE, Laeng HR, Groscurth P. Lymphatic capillaries in the meninges oft he human optic nerve. J Neuroophthalmol. 1999;19: 1365-72.

4. Mathieu E, Gupta N, Ahari A, et al. Evidence for cerebrospinal fluid entry into the optic nerve via a glymphatic pathway. Invest Ophthalmol Vis Sci. 2017;58:4784-91.

5. Carreon $\mathrm{T}$, van der Merwe $\mathrm{E}$, Fellman RL, Johnstone $\mathrm{M}$, Bhattacharya SK. Aqueous outflow-a continuum from trabecular meshwork to episcleral veins. Prog Retin Eye Res. 2017;57:108-33. 